\title{
Dependência química e trabalho: uso funcional e disfuncional de drogas nos contextos laborais
}

\author{
Drug addiction and work: functional and disfunctional drug \\ usage in labor contexts
}

\author{
${ }^{1}$ Professora Associada ao Departa- \\ zonte, MG. \\ Contato: \\ Rua Califórnia, 390 ap. 101 \\ Bairro Sion \\ Belo Horizonte, MG \\ CEP: 30315-500 \\ E-mail: \\ antuneslima15@gmail.com
} mento de Psicologia da Universidade Federal de Minas Gerais, Belo Hori-

\section{Resumo}

O objeto central do artigo é o uso de drogas nos contextos de trabalho, sendo seu objetivo maior analisar desde o uso continuado, mas sem acarretar consequências mais graves para o usuário, até aquele que leva ao desenvolvimento de uma dependência propriamente dita. A partir de uma revisão da literatura pertinente ao tema, propõe-se uma reflexão que, entre outros aspectos, classifica o consumo de drogas em dois modos, funcional e disfuncional, sendo que, no primeiro, esta é usada como uma "ferramenta" de trabalho, sem acarretar prejuízos para sua realização e, no segundo, ocorre uma mudança no padrão de consumo, afetando gravemente o desempenho profissional. Na passagem entre o uso funcional e o uso disfuncional, a droga deixa de ser um meio para se tornar um fim em si mesmo e, embora isso não ocorra com a maioria dos usuários, a conclusão é a de que, mesmo no uso funcional, a relação do sujeito com sua atividade é basicamente adaptativa, não podendo, portanto, ser considerada como saudável.

Palavras-chave: drogas; trabalho; dependência química.

\begin{abstract}
The theme of this article is drug use in work context, and the objective is to analyze it from continuous use that does not bring severe consequences to the user to use that leads to his/her addiction. Based on literature review concerning this subject, a reflexion is proposed, which, among other aspects, includes a classification of drug intake in functional and dysfunctional manners. In the first, drug is used as a "work tool" and it does not prevent work from being accomplished; in the second, there is a change of the drug consumption pattern that deeply affects professional performance. While transitioning from functional to dysfunctional uses, drug transforms from a means to an end to the end itself. However, even in functional use, the users' relationship with their activities can be basically adaptive (although this might not occur to most of them), and therefore, it cannot be considered healthy.
\end{abstract}

Keywords: drugs; work; drug addiction. 
"O primeiro fumava maconha na colheita da cana porque 'ficava com o corpo mais leve, dava vontade de trabalhar'. O segundo escondia cachaça na sua mochila. 'Quanto mais eu bebia mais tinha energia. Eu me sentia forte'. O terceiro 'ia embora' com maconha ou crack (...) 'Quando usava ninguém me segurava. Cortei vinte e uma toneladas em um dia.." (trabalhadores do cultivo da cana) ${ }^{2}$

\section{Introdução}

De início, cabe ressaltar que as duas ideias centrais contidas no título deste artigo são fontes de consideráveis controvérsias. A noção de dependência que já vem sendo questionada há algumas décadas tornou-se alvo de uma polêmica ainda mais acirrada ao ser posta em relação com o trabalho. Ou seja, a associação quase imediata que se faz normalmente entre o uso de drogas e a dependência química (ou psíquica) tem sido objeto de discussões entre os pesquisadores. A partir do momento em que pesquisas demonstraram que essa relação não é inevitável, a polêmica se instalou, colocando em dúvida o caráter exclusivamente patológico atribuído às drogas. ${ }^{3}$

Quando se trata da relação entre uso de drogas e trabalho, as discordâncias não são menos importantes, visto ser bastante comum a ideia de que esse uso não tem qualquer relação com as exigências laborais, mas com as características pessoais do sujeito, forjadas pelas experiências anteriores à sua inserção profissional. Entre aqueles que admitem sua relação com o trabalho, há a tese sobre a existência de um uso funcional ao lado de um uso disfuncional dessas substâncias. De acordo com os adeptos dessa tese, tal uso não pode ser percebido como uma experiência estritamente negativa, podendo, sob certas condições, permitir que o trabalhador lide melhor com as exigências impostas pelas suas tarefas e permaneça no trabalho. ${ }^{4}$

No entanto, até os mais ferrenhos opositores da associação imediata que se faz entre dependência e consumo de drogas - e mesmo aqueles que percebem uma funcionalidade no seu uso nos contextos de trabalho - terminam por admitir que, para certa porcentagem de indivíduos, esse uso deixa de ser funcional e uma relação de "dependência" se instala, sendo que a droga deixa de ser um meio ou um recurso a mais para o indivíduo lidar com suas dificuldades, tornando-se um fim em si mesmo. Nesse caso, ao invés de auxiliá-lo no enfrentamento dos seus problemas, é a própria substância que passa a representar um problema a ser enfrentado.

Neste artigo pretendemos propor uma reflexão sobre o tema, mas cabe esclarecer, desde já, que esta se baseia apenas parcialmente em resultados de nossas próprias investigações, sendo, em grande medida, resultante de uma revisão bibliográfica. Esta última também tem um caráter parcial, já que nosso propósito não é o de abordar exaustivamente a literatura, mas sim o de trazer aqueles elementos tratados pelos autores que permitam avançar na compreensão do nosso problema. Dessa forma, ao invés de abordar os teóricos considerados como "clássicos" no tratamento do tema, preferimos privilegiar aqueles que, no nosso entender, mais se aproximaram da questão aqui tratada, isto é, do uso de drogas nos contextos de trabalho. Como foi na produção recente francesa que encontramos a contribuição mais interessante, optamos por expô-la aqui, mesmo cientes de que ela está longe de esgotar o assunto, além de não dar conta da nossa realidade, tão diversa da europeia. Apesar disso, ela oferece excelentes pistas para futuras pesquisas, mesmo deixando claro o caráter ainda incipiente das análises, se considerarmos que estas venham de um país que se encontra muitas décadas à nossa frente nesse tipo de discussão.

\footnotetext{
${ }^{2}$ Depoimentos de trabalhadores em tratamento em um centro de recuperação de dependentes químicos de Barrinha-SP, publicados em matéria da Folha de São Paulo (MAGALHÃES; SILVA, 2008).

${ }^{3}$ Como não é nossa intenção abordar exaustivamente essa questão, acrescentamos apenas que a maioria dos autores tem abordado a polêmica em torno da dependência do álcool, localizando seu surgimento a partir dos anos 60 do século passado, quando estudos começaram a demonstrar que alguns indivíduos considerados dependentes conseguiram passar para um padrão moderado de consumo da bebida (VAILLANT, 1999; NADEAU, 1990; LEGRAND, 1997; CASTELAIN, 1989). Posteriormente, com a divulgação de pesquisas em torno do uso controlado da cocaína, ela se estendeu para as outras drogas (FONTAINE, 2006).

${ }^{4} \mathrm{~A}$ partir dos resultados alcançados por diversos estudos em torno do uso do álcool no trabalho, nossa equipe de pesquisa foi gradativamente constatando esse dado e aderindo a essa tese (SILVA, 2006; PORTES, 2006; MURTA, 2007), que está também presente em outras pesquisas, seja em torno do uso do álcool (CASTELAIN, 1989; LEGRAND, 1997) ou de drogas em geral (FONTAINE, 2006). Mas é importante esclarecer que a adoção do termo "funcional", tanto por nós, quanto por esses autores, não implica em qualquer forma de adesão a uma perspectiva funcionalista. Esse termo refere-se apenas ao fato de que o uso de droga no trabalho não é gratuito nem aleatório, mas tem uma finalidade, geralmente associada à busca de uma melhor maneira de realizar sua atividade. Nesse caso, ela se torna uma "ferramenta" de trabalho, assumindo uma "função" para o sujeito na medida em que the permite alcançar certos objetivos em geral associados à qualidade da tarefa.
} 


\section{O uso de drogas no trabalho}

Embora a associação entre substâncias psicoativas e trabalho seja um fenômeno antigo, foi apenas recentemente que passou a ser considerado como um objeto de estudo. ${ }^{5}$ Em uma edição especialmente dedicada ao tema, a revista Swaps (2009) deixou patente a importância adquirida pelo tema nos últimos anos ao lhe dedicar uma ampla reportagem. $\mathrm{O}$ foco foi, sobretudo, o uso crescente de drogas entre advogados e homens de negócios londrinos e franceses. De imediato, foi estabelecida uma relação entre esse aumento e a "atual conjuntura econômica global extremamente difícil", ao afirmar que esses profissionais estão sendo progressivamente expostos aos "sobressaltos da economia" e "submetendo-se a pressões mais fortes do que anteriormente". Assim, conclui-se que:

não é nada surpreendente que alguns deles busquem cada vez mais apoio nas drogas conhecidas por serem poderosos estimulantes intelectuais e físicos - como as anfetaminas, a cocaína, - ou procurem conforto no álcool. (p. 18)

Mas no contexto francês, talvez tenha sido Fontaine (2006) quem mais avançou nessa questão ao realizar uma pesquisa voltada exclusivamente para o tema, apesar do enfoque bastante específico. Ela estudou apenas indivíduos que, embora façam uso de drogas durante muito tempo, não têm seu desempenho profissional afetado, conseguindo equilibrar com perfeição o que chamou de "dupla vida". Por meio dessa pesquisa, a autora se inseriu na polêmica já citada anteriormente em torno da relação imediata que em geral se estabelece entre uso de drogas e dependência. Já no prefácio da obra, Albert Ogien ressaltou o caráter inovador dos seus achados, dizendo que, embora a sociologia tenha demonstrado que o uso de drogas não provoca a devastação e a desestruturação a ele normalmente atribuídas, continuamos presos a uma definição do termo "droga", que associa imediatamente, a todos que a consomem, quatro características: "animalidade, imoralidade, irresponsabilidade e decadência” (p. 11). Isso seria decorrente, segundo ele, da tendência de se julgar:

a gravidade do fenômeno da droga, à luz dos casos mais trágicos - aqueles que confortam a idéia da inevitabilidade da desgraça - fingindo ignorar que eles são, no entanto, os mais raros. (p. 11)
É por essa razão, que considera o livro de Fontaine como uma importante contribuição, uma vez que sua proposta consiste em ir além dessa "visão apocalíptica" a respeito da questão, a partir do seguinte postulado:

mais do que uma substância com propriedades psicotrópicas particulares, a droga nomeia uma forma de experiência, isto é, ela remete a um processo de familiarização com as regras que se convém respeitar para participar de um dado mundo social. E essa experiência varia segundo as circunstâncias: ela pode ser igualmente elaborada, calmante, dolorosa, não problemática, catastrófica, degradante, mortal, banal ou entediante. (p. 12)

Embora a pesquisa da autora se restrinja ao seu país, o que, obviamente, limita seu alcance para a compreensão do mesmo fenômeno em outros contextos, sobretudo no Brasil, pelas suas consideráveis diferenças em relação à França e à Europa como um todo, concluímos ser válido reportar aqui seus principais resultados, em especial pelo enfoque inovador dado ao problema. De fato, a autora traz vários depoimentos de sujeitos que, embora façam uso quotidiano de drogas, continuam a exercer sem maiores problemas suas profissões, o que lhe permitiu concluir que, na medida em que esse uso se traduza em uma "conduta regular e bastante controlada, a dependência, não é nem um destino nem um estado patológico conduzindo forçosamente à marginalidade e à morte" (p. 13). São pessoas que, segundo ela, trabalham e, paralelamente, fazem uso de drogas, mas sem que isso as coloque em evidência, na medida em que preservam seu "poder aquisitivo, um senso de discrição, uma cobertura social, eventualmente uma família e um médico" (p. 13) que as acompanha em seus problemas de saúde. Dessa forma, tornam-se praticamente despercebidas, já que não se constituem em um problema, isto é, não se afastam do trabalho por questões relativas à saúde, não se atrasam ou faltam, nem provocam "uma epidemia de acidentes de trabalho", tornando-se um peso para o Estado no plano "sanitário, financeiro ou repressivo" (p. 20). Isso lhe permitiu concluir que, nesses casos, a droga representa uma forma de "prazer, de necessidade ou mesmo um hábito", não impedindo que permaneçam como "pessoas socialmente integradas e anônimas” (p. 12), sobretudo, por não serem consideradas como um problema social, de saúde ou de ordem pública: "a integração social pelo trabalho é suficiente para que não sejam assimiladas a um perigo em potencial” (p. 19).

\footnotetext{
${ }^{5}$ Uma jornada organizada pelo CNAM (França), em Outubro de 2009, especialmente voltada para essa questão, tratou do uso de drogas associado ao trabalho em sociedades tradicionais - como é caso do consumo da coca pelos índios peruanos e bolivianos desde o período pré-colombiano - mas ressaltou, sobretudo, sua importância na atualidade. Assim, a cocaína - considerada como a "droga da performance e da energia", ao dar "a ilusão de que somos capazes de tudo", foi posta como uma substância que "se casa bem com os tempos atuais" (JOURNÉE THÉMATIQUE: DE LA COCA À LA COCAïNE, 15 out. 2009, Paris: Conservatoire National des Arts et Métiers, 2009).

${ }^{6}$ Apenas por uma questão prática e em decorrência do espaço necessariamente restrito de um artigo, decidimos incluir o álcool nesse conjunto de substâncias psicoativas, normalmente nomeadas "drogas". No entanto, estamos cientes de suas diferenças e que estas não se restringem ao fato de serem lícitas ou ilícitas.
} 
A esse respeito, vale a pena reportar aqui a definição atribuída na França a essa parcela da população vista como composta por "usuários não frequentando qualquer estrutura de assistência sanitária ou social ou não identificados pelo dispositivo de aplicação da lei” (p. 20). Nos termos de Fontaine (id. ib.), os sujeitos sobre os quais seu estudo se debruçou:

conjugam há mais de um ano - e, em alguns casos, entre quinze e vinte anos - uma prática proibida com sua inscrição em um meio profissional. Com o tempo, eles desenvolveram um bom conhecimento a respeito das drogas que utilizam, de si mesmos e de suas reações. Eles levam em conta sua sensibilidade individual, refletem sobre seu consumo e o descrevem, às vezes, como um meio de conservar um equilíbrio necessário entre sua vida interior e sua vida social. (p. 22)

Já no contexto brasileiro, esse tema é ainda muito pouco estudado e divulgado, sendo mais tratado pela mídia do que por estudos acadêmicos. Apesar disso, ele tem se imposto cada vez mais como um problema que merece ser aprofundado e melhor desvendado, o que, provavelmente, irá redirecionar as pesquisas. ${ }^{7}$

\section{Uso "funcional" de drogas nos contextos de trabalho}

No seu estudo, Fontaine (2006, op. cit.) constatou duas tendências entre os usuários de drogas que trabalham: reservar o uso das substâncias "para o tempo livre e privado, dissociado do universo profissional" ou fazer esse uso no contexto de trabalho "como um suporte, uma ferramenta ou ainda como uma necessidade” (p. 29). No primeiro caso, segundo ela, "o uso da droga não ocorre jamais (ou muito raramente) durante o tempo de trabalho, mas com frequência imediatamente após a jornada ou nos fins de semana (...)” (p. 29). Assim, a maconha, por exemplo, pode ser usada para “relaxar após o trabalho" (p. 20). No segundo caso, eles procuram mais uma sensação de euforia, "que deve permanecer sutil e interiorizada”, do que uma mudança maior, pois se trata de "se dar prazer trabalhando", de "encontrar uma forma de se entusiasmar apesar de tudo" e "já que é necessário" estar ali, tentar se "enganar voluntariamente modificando seu estado de consciência” (p. 29-30). Trata-se aqui do uso de droga como uma espécie de "lubrificante", como é o caso de um garçom que bebia "para suportar as pessoas no trabalho", tentando administrar a quantidade ingerida de modo a não impedir que executasse suas tarefas a contento.
A autora conclui que as condições de trabalho, ao se tornarem cada vez mais duras, geram um aumento das situações de:

estresse ligadas à atividade profissional, decorrente de um desinteresse pelo trabalho efetuado, do fato de exercer uma atividade insuportável - tanto física quanto psicologicamente - da sensação de 'perder sua vida ao ganhá-la', sendo o trabalho percebido como um entrave ao desenvolvimento pessoal. (p. 31)

Nesses casos:

os horários e esforços frequentemente indispensáveis para se apresentar e participar da vida interna da empresa (polidez, bom humor, maneira de se vestir, atenção dada aos colegas de trabalho) são vividos como formas de pressão. (p. 31)

\section{Além disso:}

uma degradação das condições de trabalho, uma perda do status, uma ausência de reconhecimento, podem induzir a uma perda de sentido do trabalho ou mesmo a comportamentos percebidos como típicos da doença mental (p. 32).

É possível entender, então, o uso de medicamentos e psicotrópicos como uma prática de "modificação dos estados de consciência” não exatamente voltada para a obtenção do prazer, "mas para aliviar a carga da responsabilidade que se torna demasiadamente pesada” (p. 32).

Assim, quando se trata do consumo dessas substâncias nos contextos de trabalho, Fontaine (2006, op. cit.) observa com frequência uma representação do próprio corpo como:

um veículo, ao mesmo tempo portador da imagem social, transmissor de moléculas químicas destinadas a modificar o espírito, a consciência, produtor da força de trabalho e depositário dos riscos assumidos e dos danos sofridos durante toda a vida. (p. 33)

Nesse caso, a droga é usada como um "carburante" para um "corpo-máquina” que precisa ser reativado constantemente (p. 13).

Uma boa ilustração disso encontra-se no depoimento do gerente de um restaurante e de uma sala de concertos, de 48 anos:

O consumo de heroína é totalmente compatível com minha atividade profissional. [...] Eu acho que a clientela, as pessoas com quem convivo, inclusive o patrão, ninguém jamais percebeu. [...] Mas em uma profissão como a minha, no ritmo que eu a exercia, infelizmente, (a heroína) tornou-se um motor. Quer dizer, era o que me fazia levantar de manhã, o que

\footnotetext{
${ }^{7}$ Tratamos dessa questão em uma publicação (LIMA, 2003), na qual citamos algumas reportagens veiculadas pela mídia nacional em torno do uso de drogas em contextos específicos de trabalho, tais como: o uso da cocaína entre executivos nos anos 1980 e o uso da morfina entre os médicos. Mais recentemente, uma reportagem da revista Veja (EMPREGADOS do vício. Veja Brasil, n. 1935, p. 82, 1 mar. 2006) abordou, de forma mais detalhada, como certas drogas podem ser privilegiadas por algumas categorias profissionais: cocaína, álcool e anfetaminas, entre os operadores da bolsa de valores; anfetaminas e álcool entre motoristas de ônibus e caminhão; cocaína e álcool entre publicitários; cocaína e álcool entre jornalistas; opiáceos e calmantes entre médicos e enfermeiros; álcool e anfetaminas entre advogados. Além disso, a reportagem citada na epígrafe deste artigo, publicada pela Folha de São Paulo (MAGALHÃES; SILVA, op. cit.), descreve com riqueza de detalhes a situação de trabalho dos cortadores de cana e a forma pela qual têm recorrido a diversos tipos de droga (crack, maconha, álcool) para conseguirem responder às exigências impostas pela sua atividade.
} 
me fazia 'arrancar'. Eu não podia trabalhar sem heroína. Quando você pára não pode mais andar, não pode fazer mais nada, sente dores por todo o corpo. Portanto, você entra nesse processo [...] e se não tem tempo de dar um 'break' você continua até as próximas férias. [...] Quando as pessoas estão habituadas com certo comportamento seu, elas só se sentem chocadas se você mudar o comportamento. Se elas me encontrassem às 10 horas da manhã - no momento em que você começa a não se sentir bem - aí ficariam chocadas e me achariam doente, estranho. Mas como te vêem sempre no momento em que reativou a máquina, elas te acham bem, te acham normal. [...] Contrariamente à cocaína que tem um efeito estimulante, a heroína é um relaxante. [...] É alguma coisa de muito dinâmico que apaga enormemente a fadiga, que te permite se concentrar. Você está concentrado, mas sem o nervosismo da cocaína. Você se sente bem consigo mesmo, não sente qualquer mal estar, é paciente e sociável. [...] Em jornadas de quatorze ou quinze horas de trabalho, isso me permite não ver as horas passarem. [...] (p. 33-34) ${ }^{8}$

Entendemos que esse depoimento ilustra bem o que estamos chamando aqui de uso funcional da droga no trabalho, mas, em alguns casos, ainda que esse uso ocorra fora desse contexto, isto é, após o término da jornada ou nos fins de semana, a relação com a atividade laboral não deixa de ser admitida. É o que vemos, por exemplo, no depoimento de um comerciário de 24 anos de idade que se diverte vários dias da semana usando tabaco, cocaína e ecstasy como estimulantes, já que deve acordar às 7 horas da manhã e sua renda depende, em grande parte, das vendas que realiza:

O uso das drogas me permite viver a noite nos fins de semana e viver o dia durante a semana. Porque existe a pressão do trabalho na semana e depois o desligamento do fim de semana. (...) Você volta para casa na segunda de manhã entre 6 e 7 horas, toma uma ducha, um café e vai para o trabalho. Eu não consumo no trabalho, com exceção de um pouco de álcool ao meio dia, especialmente com certos clientes com quem almoço. Mas esse consumo implicitamente faz parte do meu trabalho. As outras drogas eu reservo para o fim de semana. (...) Meu uso não é diretamente ligado ao trabalho. Prefiro usar a droga para sair e festejar do que ser obrigado a usar drogas para aumentar o meu rendimento profissional. Mas evidentemente, é a atividade profissional da semana que faz com que eu sinta necessidade de alguma coisa para sair à noite... pois certamente você deseja ter uma vida após o trabalho. (p. 35-36)

Ou no caso de um barman que trabalhava à noite diversas vezes por semana, em uma jornada extensa que o obrigava, em certos dias, a ficar disponível por cerca de 20 horas e disse consumir a cocaína como forma de "unir o trabalho ao agradável” (p. 36). Para ele, a droga atuava como uma espécie de "bônus" após um longo período de atividade:

Era um trabalho muito duro, com momentos difíceis e que precisava suportar. A gente não tinha um salário fixo e recebia uma porcentagem, 11\%, sobre o que vendia. [...] Mas uma vez que você o conhecia bem e conseguia administrá-lo mesmo nos dias de rush, você cheirava uma fileira de cocaína como um bônus. (p. 36)

Além disso, Fontaine (2006, op. cit.) constatou no seu estudo um uso quase exclusivo de estimulantes que modificam pouco o estado de consciência (anfetaminas, guaraná, café, tabaco) quando os sujeitos pretendiam "aumentar a capacidade de trabalho e lutar contra a fadiga”, enquanto que o uso do álcool e dos psicotrópicos ilícitos visava sempre "um estado modificado de consciência” (p. 37). Em outros termos, ao recorrer a esse tipo de droga, o indivíduo "visa essencialmente não a melhora do seu desempenho, mas o alcance de um estado de espírito que lhe permita aceitar mais serenamente as regras do trabalho e submeter-se a elas" (p. 37). E, no caso daqueles que consomem durante a jornada, "o uso dos psicotrópicos permite 'suportar melhor o trabalho', 'suportar melhor os outros', 'enganar o tédio', 'não ver as horas passarem' ou ainda 'se suportar melhor no trabalho”' (p. 37). Trata-se, portanto:

de confundir voluntariamente suas percepções não forçosamente para trabalhar mais ou melhor, mas para 'se dar os meios para fazê-lo' ao conter um nervosismo, uma irritabilidade ou simplesmente um mau humor que podem afetar consideravelmente as relações profissionais. (p. 37-38)

É nesse sentido que dois sujeitos que atuam no ramo cultural - e que são frequentemente obrigados a "passar a noite em claro" - falam do uso da cocaína e do ecstasy, que "consomem em pequena quantidade, para se manterem acordados, mas também para serem eficazes no plano relacional" (FONTAINE, id. p. 38). Outro sujeito se descreve como dopado no trabalho, dizendo que o consumo da maconha é para ele uma condição para ir trabalhar e se mostrar sociável. Segundo ele, jamais se dirige ao trabalho sem ter fumado, pois, sem a maconha, tudo se tornaria insuportável (id. p. 38).

Os resultados da pesquisa realizada por Fontaine sugerem, em suma, que o recurso aos psicotrópicos é percebido, às vezes, como uma solução eficaz para suportar as exigências impostas pelo trabalho, sendo que sua ação, descrita sob esse prisma, concerne a três tipos de efeitos estreitamente interligados: a desinibição, "que pode se revelar útil no quadro profissional, no sentido em que proporciona certa euforia, uma maior facilidade para comunicar, uma tendência a exteriorizar as emoções e uma maior confiança em si mesmo"; em seguida, o fato de que "todas as drogas têm em comum, ainda que em intensidades diversas, a faculdade de alterar a noção do tempo", permitindo a sensação de "não ver o tempo passar"; finalmente, o papel importante que têm sobre a concentração, já que permitem um desligamento dos estímulos externos, ainda que isto envolva sempre o risco de o sujeito ser “absorvido pelo seu mundo interior” (id. p. 37-38).

${ }^{8}$ Todos os grifos nesta fala e nas subsequentes são nossos. 
Alguns depoimentos dos advogados londrinos e franceses, já citados anteriormente, são igualmente reveladores desse caráter funcional da droga em certos contextos de trabalho (SWAPS, 2009). Uma advogada francesa, por exemplo, disse que a cocaína é "bastante tolerada" nesse meio profissional, já que ela permite que a pessoa permaneça "em forma”, sentindo como "se tivesse uma verdadeira vida, enquanto passa seus dias e noites no escritório” (p. 19). Nesse caso, acrescenta ela, "vale mais se iludir", pois não é "forçosamente normal querer trabalhar quinze horas por dia". E finaliza dizendo que "a coca é a droga perfeita para se inflamar, sobretudo, quando a gente é advogado no ramo de negócios [...] onde se quer sempre ser o (ou a) melhor" (p. 19). Dessa forma, ao atuar em um ambiente cada vez mais opressivo, que passa por um "verdadeiro período de turbulência”, esses advogados teriam dificuldades em admitir diante dos colegas "sua incapacidade de se adaptar”, já que temem ser considerados como a "parte fraca" do sistema (p. 19).

Um deles expressou bem a dimensão assumida pelo problema ao admitir ter consumido 100.000 libras em cocaína em apenas um ano: "eu abusei bastante da droga, usando grandes quantidades de cocaína, a tal ponto que eu não era mais eu mesmo cinco dias por semana”. Além disso, acrescenta ele:

a droga entre os advogados não se limita em nenhum caso ao uso fora do escritório, nem em alguma atividade pós-trabalho. Eu usava a droga antes de ir ao trabalho, no escritório e também depois.

Um advogado francês que assumiu ter "usado e abusado do álcool e dos antidepressivos”, já que essas substâncias lhe traziam "conforto", disse: "eu sentia naquele momento uma enorme fadiga e necessitava de um estimulante capaz de bloquear os efeitos da sobrecarga; eu precisava pisar no acelerador e não tinha mais nada". Sobre a indiferença dos responsáveis pelos escritórios a respeito do problema - apesar dos seus sinais claros e alarmantes - outro disse que, entre os advogados, ao contrário de outras profissões mais clássicas, como a medicina e o ensino, costuma-se não dar qualquer importância ao fato desde que o profissional continue produzindo. Um terceiro, que fazia uso de cocaína, disse que, ao se tornar viciado, sua personalidade mudou de maneira brutal, mas acrescentou que ninguém prestou atenção porque continuava a ganhar dinheiro e a trazer lucro para o escritório.

Talvez o depoimento mais revelador do caráter funcional da droga nesse contexto tenha sido o de um advogado londrino, usuário de haxixe e, ocasionalmente, de cocaína, que estabeleceu uma espécie de "tipologia” dos consumidores de drogas no seu meio. Segundo ele:

existe o colaborador que usa de tempos em tempos para suportar o tranco já que ele trabalha até tarde da noite. [...] Ele usa a droga à meia noite para passar um bom momento, mas não é alguém completamente excitado, ligado. Em seguida, existe o grande associado, muito importante, e que usa com muita frequência. Ele tem o hábito de sair para almoços e jantares de negócios. Para ele, a cocaína faz parte da excitação do trabalho e, além disso, tem menos necessidade de se assegurar intelectualmente. Deve apenas falar na linguagem dos negócios e não fica diante do seu computador analisando contratos. Enfim, o terceiro tipo [...] é o colaborador sênior, não muito seguro de si, que tem certa imagem da profissão, segundo a qual todos os advogados usam drogas. No início, ele consome um pouco. Começa a ganhar dinheiro e aí fica mais fácil. [...] Esse tipo de pessoa não usa apenas a coca, mas também as anfetaminas. Rapidamente ela perde o controle. (p. 19)

O diretor de um órgão que coordena diversos grupos de reflexão com dirigentes de escritórios franceses de advocacia fez uma interessante análise dessa questão ao dizer que o tema do uso de drogas na categoria é frequentemente abordado, sendo as adições mais severas o problema que atinge cada vez mais os escritórios, tanto entre os associados, quanto com os colaboradores. Segundo ele:

pode-se ver nisso um sinal de um mal estar geral, bem anterior à crise econômica e que é devido, sobretudo, ao desequilíbrio entre vida profissional e vida privada, à pressão quanto às horas e ao rendimento e, de uma maneira geral, ao ambiente de competição induzido em muitos escritórios. As pessoas devem suportar o ritmo no longo prazo e permanecerem no topo. Pelo estado de nervosismo e pelos olhos vermelhos de alguns [...] pode-se imaginar facilmente como é que suportam. (p. 20)

Além das chamadas drogas ilícitas, o álcool é bastante usado nos contextos de trabalho, sendo este um tema sobre o qual os pesquisadores têm se dedicado mais, explicitando algumas de suas "funções". Observa-se que essa substância pode representar também um recurso essencial para que o trabalhador suporte as exigências impostas pela sua atividade, podendo ser vista como uma verdadeira ferramenta de trabalho. Assim, os estudos que realizamos junto a diversas categorias profissionais (motoristas e cobradores de ônibus urbano, trabalhadores da construção civil, policiais militares, coletores de lixo) permitiram não apenas a explicitação do lugar específico ocupado pela bebida em cada uma delas, como também identificar alguns aspectos comuns (ALVES, 2007; AMARAL, 2005; GISCHEWSKI, 2004; MURTA, 2007; PORTES, 2006; SILVA, 2004; SILVA, 2006; TENAGLIA, 2004). ${ }^{9}$ Dessa forma, o álcool pode ser usado como um recurso: para reduzir o sentimento de impotência diante de uma organização rígida de trabalho e onde a contabilidade psíquica do oferecido e do recebido (LE GUILLANT, 2006) quase sempre favorece o primeiro (motoristas, cobradores, trabalhadores

\footnotetext{
${ }^{9}$ Pesquisas realizadas dentro do Programa de Pós-Graduação do Departamento de Psicologia da UFMG sob nossa coordenação e cujos resultados serão divulgados em uma coletânea voltada para discutir a relação entre alcoolismo e trabalho.
} 
da construção civil, policiais, coletores de lixo); para reduzir o sentimento de frustração acumulado durante toda a existência devido à falta de perspectiva de crescimento profissional e pessoal (cobradores, trabalhadores da construção civil, coletores de lixo); para combater os efeitos da autoestima rebaixada devido ao não reconhecimento no trabalho (policiais, trabalhadores da construção civil, coletores de lixo, cobradores); para obter uma satisfação compensatória, anestesiando o sofrimento psíquico e, ao mesmo tempo, evitando a tomada de consciência de uma situação penosa (trabalhadores da construção civil, cobradores, coletores de lixo); para reduzir o medo ou os efeitos dos traumas decorrentes de situações de violência e da necessidade de cumprir tarefas que envolvam riscos (motoristas, cobradores, trabalhadores da construção civil, policiais). ${ }^{10}$

\section{Uso "disfuncional" de drogas nos con- textos de trabalho}

Em diversos casos analisados, tanto por nós, quanto por outros pesquisadores, observa-se que, após certo tempo de uso da substância, um círculo vicioso se instala: a droga deixa de ser um meio para lidar com as dificuldades, passando a ser um fim em si mesmo. Ao estudar o consumo de bebidas alcoólicas, Legrand (1997) constatou o que chamou de perversão da finalidade. Segundo ele, isso ocorre quando o ato de beber se torna seu próprio fim e a pessoa passa a beber por beber. Dessa forma, o que era um meio para se alcançar um fim passa a ser sua própria finalidade, indicando que o uso da bebida, inicialmente investido de boas razões, passa a se manter por si mesmo por meio de pretextos autojustificativos (p. 59). Ocorre, nesse caso, uma espécie de armadilha circular que tende, segundo o autor, a se alimentar indefinidamente, em um circuito cada vez mais fechado, fazendo eclodir o absurdo, o insensato (p. 59). Ele denomina esse processo de ciclo do alcoolismo, dizendo que a alcoolização acaba por cultivar os problemas para os quais ela foi de início solicitada enquanto remédio ou solução. De modo que a solução se torna problema e, assim, se autoperpetua (p. 60). O autor considera também que esse modelo pode ir além do alcoolismo, alcançando as toxicomanias em geral. Ele reforça essa ideia com a tese de um especialista em toxicomanias (MENDES, 1992 apud LEGRAND, 1997) que propõe o que chama de círculo vicioso ou impasse, no qual se encontra fechado o toxicômano que se droga para evitar os sintomas que são precisamente provocados pela droga. Ou seja, também para esse especialista, a droga pode se tornar o problema e a solução.
Quando isso ocorre nos contextos laborais, o que temos constatado é que, embora a substância, inicialmente, apresente-se como um recurso para o enfrentamento de certas exigências do trabalho, pouco a pouco, seu uso começa a acarretar novos problemas no próprio trabalho, tais como punições, transferências compulsórias, rebaixamento de função, imposição de tarefas menos interessantes ou o isolamento puro e simples do trabalhador. Tudo indica que, nesses casos, o uso continuado da substância acaba por torná-la disfuncional na medida em que, ao invés de se constituir como um auxílio ou uma ferramenta, ela passa a ser um empecilho para a realização das atividades. Um dos sinais frequentes dessa mudança consiste na desvinculação do sujeito de sua equipe (ou do seu coletivo) de trabalho. No que concerne ao uso do álcool, é comum que tal mudança se manifeste, inclusive, no seu padrão de consumo, que deixa de ser em grupo para ser cada vez mais solitário. Uma consequência disso é o isolamento crescente do trabalhador, acompanhado, muitas vezes, de uma clara hostilidade dos colegas que não reconhecem nele mais suas antigas competências, passando a considerá-lo como um fator de risco para si mesmo ou para a equipe (PIALOUX, 1992; CASTELAIN, 1989).

Entre os trabalhadores da cana que recebem tratamento em uma das diversas clínicas de recuperação recentemente criadas em São Paulo, identificamos alguns depoimentos que ilustram bem esse processo. Um deles, que havia trocado a maconha pelo crack, disse: "na roça vinha a sensação de ser perseguido, eu ficava com medo, via revólver, dava vontade de atirar em mim mesmo. Não trabalhava. Comecei a perder o serviço”. Outro revela que passou "do fermentado da cana-de-açúcar para o crack', dizendo que começou também a faltar ao trabalho. Os autores da reportagem concluem que, em geral, "os depoimentos dos lavradores associam o consumo de drogas à impressão inicial de superação dos limites físicos", isto é, "na largada, elas parecem ajudar", mas “depois debilitam” (MAGALHÃES; SILVA, 2008).

\section{À guisa de conclusão}

Ao comentar a frase de um ciclista profissional ucraniano que admitiu se dopar "para obter melhores resultados", Lowenstein (2009) afirmou que ela poderia ter sido pronunciada por vários outros profissionais que não pertencem ao meio esportivo, tais como advogados, médicos, jornalistas, altos executivos, cabeleireiros e padeiros. Com isso, o presidente da associação francesa da "SOS Adições" quis ilustrar sua experiência recente com usuários de drogas. Ele tem constatado que, nos últimos anos, outras categorias profissionais vêm se juntando àquelas que tradicionalmente faziam uso

\footnotetext{
${ }^{10}$ Nesse caso, o álcool pode ser usado para combater sintomas de outros quadros graves desencadeados pelas situações vividas no trabalho, como, por exemplo, o quadro de Transtorno de Estresse Pós-Traumático, bastante comum entre os policiais, mas que, diante da violência crescente nos grandes centros urbanos, vem acometendo outras categorias, como os motoristas e os cobradores de ônibus urbano.
} 
da cocaína após descobrirem suas "virtudes dopantes". No seu contato diário com esses pacientes, o psiquiatra francês observa que, nos últimos quinze anos, a cocaína tem saído do seu "gueto dourado" composto por "artistas, modelos, tenistas" para se "banalizar" (p. 2021). Tal banalização é de tal forma real, disse ele, que estabelecer um perfil do usuário dessa substância tornou-se tão difícil quanto estabelecer o perfil do usuário do álcool ou da maconha. Mas isso não o impede de concluir que certas categorias profissionais continuam "mais expostas do que outras" (p. 21). Para ilustrar, cita uma estatística oferecida por um centro privado norte-americano, especializado em dependência química, que revela a presença maior de alguns profissionais entre seus pacientes: advogados, médicos (sobretudo os cirurgiões e anestesistas), empresários, jornalistas e pessoal de navegação (em especial os comandantes de bordo). Ele acrescenta que, após apresentar esses dados, o diretor do hospital em questão observou: "em certas profissões a adição faz parte dos riscos profissionais" o que permitiria "requalificar a dependência como doença do trabalho" (p. 21). ${ }^{11}$

Mas cabe ressaltar que é o próprio Lowesntein (2009, op. cit.) o primeiro a reconhecer que, apesar das evidências que vêm sendo acumuladas, a França ainda se encontra bem distante de "reconhecer a adição como uma doença do trabalho”, uma vez que existe até mesmo "uma dificuldade em reconhecê-la como doença" (p. 21). É claro, esclarece ele, que:

nem todos os advogados serão dependentes de cocaína, da mesma forma que não são todas as enfermeiras que serão soropositivas [...] ao se picarem acidentalmente. Mas a pressão inerente a essa profissão, a exigência de desempenho e sua correlação positiva com o sucesso financeiro, o ritmo e as condições de trabalho [...], o acesso jovem e rápido a contratos e responsabilidades muito importantes, constituem verdadeiros fatores de risco para as adições. (p. 21)

Ele finaliza dizendo que "quanto mais uma sociedade é exigente e impõe o sucesso e a performance, mais as condutas dopantes serão prováveis” (p. 21).

Fontaine (2006) também constata a ausência de qualquer referência ao trabalho quando se aborda o uso de drogas, o que a permite concluir que "[...] o alcoolismo assim como as toxicomanias são quase sempre considerados como problemas pessoais, sem ligação com os contextos nos quais se inscrevem" (p. 20). No entanto, considera que "a esfera do trabalho assume uma posição predominante nessa questão, uma vez que é nesse contexto que as pessoas passam uma boa parte de suas vidas” (p. 20). Assim, embora tenha privilegia- do, no seu estudo, indivíduos que parecem equilibrar trabalho e consumo de drogas, a autora observou em muitos deles uma "ambivalência" na "relação que mantêm com a atividade profissional, com a droga, com sua inscrição na sociedade” (p. 21). Segundo ela:

O usuário de drogas que trabalha se encontra cotidianamente confrontado a diferentes tensões: tensão entre o desejo de se afastar do mundo, de se desconectar e de se integrar, se adaptar a ele; tensão na passagem de uma identidade social a outra, às vezes, radicalmente oposta; tensão entre a transgressão e a aceitação das normas. (p. 21-22)

Portanto, no conjunto de dados reportados por essa autora, é frequente a presença da droga como uma "ferramenta de integração" à sociedade e, em particular, ao trabalho e às suas exigências (muitas vezes excessivas), o que nos remete - para além da questão da dependência - à problemática da alienação e de sua inevitável relação com os processos saúde/doença. Se concordarmos com Canguilhem (2006) quando este afirma que a saúde é muito mais do que a mera integração a um meio, podemos concluir que tal "ferramenta" possibilita apenas uma melhor adequação às normas vigentes, inclusive àquelas impostas pelo trabalho. Ao invés de serem "normativas" (CANGUILHEM, 2006), essas pessoas estariam apenas tentando se adequar às normas. Além disso, embora seu comportamento possa ser à primeira vista qualificado como transgressor, uma vez que o consumo da droga - em especial da droga ilícita - está, evidentemente, em contradição com as regras estabelecidas, ele consiste, na verdade, em um esforço de adaptação. Assim, se tal condição não pode ser considerada como patológica, ela está também distante do que Canguilhem (id.) considerava como sinônimo de saúde. ${ }^{12}$

No Brasil, assim como vem ocorrendo no contexto francês, as evidências sobre a relação entre adição e uso de drogas no trabalho têm sido cada vez mais contundentes, embora isso não esteja conduzindo a avanços importantes no sentido do seu reconhecimento. É por essa razão que, diante da grande quantidade de casos emergindo de uma mesma situação de trabalho, a medida encontrada tem sido a de criar "clínicas de recuperação", como vimos no caso dos "trabalhadores da cana" várias vezes citado neste artigo. O depoimento de um dos quarenta internos de uma dessas clínicas revela bem a "eficácia” dessa "solução", qualificada com muita propriedade por Clot $(2008,2010)$ como uma "nova profilaxia social" ou "um novo higienismo”. Após dizer que "ficava louco”, “viajava no

\footnotetext{
${ }^{11}$ Com a finalidade de verificar a pertinência desse tipo de observação, iniciamos há um ano e meio uma pesquisa em uma instituição de atendimento a dependentes químicos, situada em Belo Horizonte (MG). O estudo se encontra em andamento, tendo sido finalizada, recentemente, a primeira etapa que consistiu na análise de cerca de 6.000 prontuários.

${ }^{12}$ De acordo com Clot, tudo indica, nesse caso, que o sujeito perdeu a saúde antes mesmo de desenvolver uma doença propriamente dita. Ou seja, para esse autor, sobretudo em situações de trabalho, é comum se constatar que muitos trabalhadores já perderam a saúde, embora ainda não se encontrem doentes (CLOT, Y. Palestra proferida na UFMG com o título "Contribuições da Clínica da Atividade para o campo da Saúde Mental e Trabalho, em setembro de 2007).
} 
serviço", "gritava e zoava a cabeça” dos colegas, esse trabalhador acrescentou que seu plano, após receber alta, é o de continuar cortando cana. Diante disso, não é surpreendente saber que a própria usina de onde saiu se encontra entre as fontes financiadoras da clínica. Com isso, fecha-se um circuito que ten-

\section{Referências}

ALVES, P. Q. O alcoolismo na atividade de trabalho do coletor de lixo: um estudo de caso. 2007. 60 f. Trabalho de Conclusão de Curso (Especialização em Psicologia do Trabalho)-Departamento de Psicologia, Universidade Federal de Minas Gerais, Minas Gerais, 2007.

AMARAL, E. L. A relação entre alcoolismo e trabalho: o caso do trocadores de transporte coletivo urbano. 2005. 73 f. Trabalho de Conclusão de Curso (Especialização em Psicologia do Trabalho)Departamento de Psicologia, Universidade Federal de Minas Gerais, Minas Gerais, 2005.

CANGUILHEM, G. O normal e o patológico. Rio de Janeiro: Forense Universitária, 2006.

CASTELAIN, J.-P. Manières de vivre manières de boire - álcool et sociabilité sur le port. Paris: Imago, 1989.

CLOT, Y. Travail et pouvoir d'agir. Paris: PUF, 2008.

Le travail à coeur: pour en finir avec les risques psychosociaux. Paris: Éditions La Découverte, 2010.

FONTAINE, A. Double vie - les drogues et le travail. Paris: Les empêcheurs de penser en rond, 2006.

GISCHEWSKI, V. O abuso do álcool entre policiais militares: um estudo de caso. 2004. 85 f. Trabalho de Conclusão de Curso (Especialização em Psicologia do Trabalho)-Departamento de Psicologia. Universidade Federal de Minas Gerais, Minas Gerais, 2004.

LEGRAND, M. Le sujet alcoolique: essai de psychologie dramatique. Paris: Désclée de Brouwer, 1997.

LE GUILLANT, L. Escritos de Louis Le Guillant: da ergoterapia à psicopatologia do trabalho. Petrópolis: Vozes, 2006.

LIMA, M. E. A. A polêmica em torno do nexo causal entre distúrbio mental e trabalho. Psicologia em Revista, v. 10, n. 14, p. 82-91, 2003.

LOWENSTEIN, W. Exposition professionnelle à la cocaïne: le regard de William Lowenstein. Swaps Santé, Réduction de Risques et Usage de Drogues, Paris, n. 56, p. 11-12, 2009. de a se autoalimentar indefinidamente, caso não seja rompida a lógica que o sustenta. Tal ruptura só será possível, no nosso entender, por meio do retorno ao mundo do trabalho, tentando identificar nele (e a partir dele) possibilidades efetivas de desenvolvimento e de emancipação.

MAGALHÃES, M.; SILVA, J. Os anti-heróis: o submundo da cana. Folha de S. Paulo, São Paulo, Caderno Mais!, 24 ago. 2008.

MURTA, E. P. A relação entre a atividade de coleta de lixo domiciliar de Belo Horizonte e o alcoolismo dos coletores de lixo: um estudo de caso. 2007. 115 f. Dissertação (Mestrado em Psicologia Social)-Departamento de Psicologia, Universidade Federal de Minas Gerais, Minas Gerais, 2007.

NADEAU, L. Vivre avec l'alcool: la consommation, les effets, les abus. Québec: Les Editions de L’Homme, 1990.

PIALOUX, M. Alcool et politique dans l'atelier d'une usine de carrosserie dans la decennia 1980. Genèses, n. 7, p. 94-128, 1992.

PORTES, P. C. P. O uso do álcool por motoristas profissionais: o caso dos transportes coletivos urbanos. 2006. 135 f. Dissertação (Mestrado em Psicologia Social)Departamento de Psicologia, Universidade Federal de Minas Gerais, Minas Gerais, 2006.

SILVA, F. B. O. A relação entre o uso do álcool e o trabalho na construção civil. 2006. 167 f. Dissertação (Mestrado em Psicologia Social)-Departamento de Psicologia, Universidade Federal de Minas Gerais, Minas Gerais, 2006.

SILVA, P. S. Alcoolismo e trabalho: estudo de caso de um motorista do transporte coletivo urbano em Belo Horizonte. 2004. 63 f. Trabalho de Conclusão de Curso (Especialização em Psicologia do Trabalho)-Departamento de Psicologia, Universidade Federal de Minas Gerais, Minas Gerais, 2004.

SWAPS - SANTE, RÉDUCTION ET USAGES DE DROGUES. Paris: Pistes, n. 56, $4^{\text {ème }}$ trimestre 2009.

TENAGLIA, M. R. Construção civil e alcoolismo: um estudo de caso realizado em empresa da construção civil de Belo Horizonte. 2004. 98 f. Trabalho de Conclusão de Curso (Especialização em Psicologia do Trabalho)Departamento de Psicologia, Universidade Federal de Minas Gerais, Minas Gerais, 2004.

VAILLANT, G. E. A história natural do alcoolismo revisitada. Porto Alegre: Artes Médicas, 1999. 